\title{
Prognostic significance of UPA and UPAR expression in patients with cervical cancer undergoing radiotherapy
}

\author{
DANUPON NANTAJIT ${ }^{1,2}$, PIYAWAN CHAILAPAKUL ${ }^{3}$, SARINYA BAWORNPATARAPAKORN $^{3}$, \\ SASIKARN CHAMCHOD ${ }^{1,3}$ and KANYANEE LAEBUA ${ }^{3}$
}

\begin{abstract}
${ }^{1}$ Faculty of Medicine and Public Health, HRH Princess Chulabhorn College of Medical Science, Chulabhorn Royal Academy, Bangkok 10210, Thailand; ${ }^{2}$ Centre for Host Microbiome Interactions, Faculty of Dentistry and Craniofacial Sciences, King's College London, London SE1 1UL, UK ${ }^{3}$ Department of Radiation Oncology,

Chulabhorn Hospital, Chulabhorn Royal Academy, Bangkok 10210, Thailand
\end{abstract}

Received November 24, 2020; Accepted March 8, 2021

DOI: 10.3892/ol.2021.12684

\begin{abstract}
Cervical cancer remains a major health threat. Urokinase serves as a marker of metastatic tumors. The present study aimed to determine whether the expression levels of urokinase plasminogen activator (uPA) and urokinase plasminogen activator receptor (uPAR), before and during the course of radiotherapy, serve as prognostic markers for patients with cervical cancer. Cervical tumor tissue biopsies were collected from 72 patients before radiotherapy and after the completion of external beam radiotherapy (EBRT) before intracavitary brachytherapy. The levels of UPA and UPAR were determined using ELISA assays. The significance of the associations between the protein expression levels and the clinical outcomes of patients was determined. Although irradiation enhanced uPA and UPAR expression in cervical cancer cell lines, average uPA levels significantly decreased in tumors, and uPAR levels significantly increased after EBRT. The levels of uPA increased in 12 patients and decreased in 26 patients; and those of uPAR increased in 13 patients and decreased in two patients. Cox regression analysis revealed that increased expression of UPAR was significantly associated with 5-year overall survival rate [hazard ratio (HR), 3.65 ; 95\% confidence interval (CI), 1.18-11.30]. However, the levels of both proteins before radiotherapy failed to predict clinical outcomes. Other significant predictive factors were partial response (HR 7.22; 95\% CI 1.17-44.73) and disease progression (HR, 13.41; 95\% CI, 1.17-153.07). These findings indicated that increased expression of UPAR in cervical tumor tissue during radiotherapy may serve as a prognostic marker for patients with cervical cancer.
\end{abstract}

Correspondence to: Dr Kanyanee Laebua, Department of Radiation Oncology, Chulabhorn Hospital, Chulabhorn Royal Academy, 906 Kamphaeng Phet 6 Road, Lak Si, Bangkok 10210, Thailand E-mail: kanyanee.lae@pccms.ac.th

Key words: urokinase, cervical cancer, radiotherapy, prognosis, radioadaptive response

\section{Introduction}

A major obstacle to cancer treatment is the adaptive resistance of tumor cells, and alterations in the regulation of gene expression caused by therapeutic stress may lead to treatment failure (1). Several mechanisms, including upregulation of gene expression and activation of signal transducers, defend cancer cells against radiation to confer a survival advantage. These events induce the expression of genes encoding molecules that promote survival, repair DNA damage, induce inflammation and inhibit apoptosis $(2,3)$.

The expression of genes that encode components of the urokinase system is associated with the diagnosis and prognosis of cancer of the breast, gastrointestinal tract, colon and rectum, esophagus, kidneys, endometrium and ovaries $(4,5)$. The urokinase system comprises of urokinase-type plasminogen activator (uPA), tissue plasminogen activator (tPA), urokinase plasminogen activator receptor (UPAR) and the plasminogen activator inhibitors (PAI)-1 and -2 (6). Similar to matrix metalloproteinases, urokinase principally induces lysis of the basement membrane and the extracellular matrix during tissue remodeling, which confers upon urokinase multifunctional roles in neoplastic and malignant transformation, tumor angiogenesis, tumor progression and metastasis (7).

The transcription of the gene encoding $\mathrm{UPA}$, which mediates metastasis, is activated by transcription factors such as AP1, erythroblast transformation specific-1 (Ets-1) and Ets-2 (8). Furthermore, uPA is involved in tissue remodeling (9). The expression of its receptor uPAR (also known as CD87), a glycosyl phosphatidylinositol-anchor protein, is regulated by transcription factors such as $\mathrm{Sp} 1, \mathrm{NF}-\mathrm{\kappa B}, \mathrm{TCF}$, hypoxia-inducible factor-1 $\alpha$ and forkhead box protein (Fox) M1 $(6,10)$. The main functions of uPAR involve the regulation of extracellular proteolysis and cell-extracellular matrix interactions (11). Upregulation of the expression of uPAR and uPA enhances tumor progression as well as the aggressiveness of numerous cancer cell types such as lung, breast and stomach cancer (12). Furthermore, uPAs serve as biomarkers and targets for treatment of human malignancies such as breast and pancreatic cancer (13). For example, the expression levels of UPA and PAI-1 are recommended by the American Society 
of Clinical Oncology as markers for selecting a regimen to treat patients with node-negative breast cancer and to predict metastasis (14).

Cervical cancer remains a major public health problem for women in developing countries, where it has caused $\sim 270,000$ deaths annually worldwide as of 2018 (15). In total, $\sim 5 \%$ of all human cancer cases are caused by infection with human papillomavirus (HPV), and most are cancer cases are of the cervix (16). Despite the development and availability of HPV vaccines, oncogenic HPVs are detected by cervical cancer screening programs (17). Expression of UPA and PAI-1 correlates with the prognosis of patients with cervical cancer, and HPV16 E6 induces cancer cells to migrate following the activation of uPA $(18,19)$. Furthermore, uPA serves as a prognostic marker for the metastatic potential of cervical cancer (20).

The present study therefore reasoned that investigation of the components of the uPA system and their relationship with resistance to therapy may improve the outcomes of patients with cervical cancer. To provide support for this hypothesis, whether irradiation enhanced the expression of uPA and uPAR in patient tissue samples and cell lines and whether such changes predicted patients' clinical outcomes were investigated.

\section{Materials and methods}

Antibodies and reagents. Antibodies against uPAR, Ets-1 and FoxM1 (cat. nos. 12863, 14069 and 5436, respectively) were purchased from Cell Signaling Technology, Inc., anti-GAPDH (cat. no. MA5-15738) was purchased from Thermo Fisher Scientific, Inc. and anti-uPA (cat. no. MAB7776) was purchased from EMD Millipore. Secondary antibodies, goat anti-mouse $\operatorname{IgG}$ peroxidase conjugated (cat. no. AP124P) and goat anti-rabbit IgG peroxidase conjugated (cat. no. AP132P), were purchased from EMD Millipore. RIPA cell lysis buffer and ECL solution were purchased from Merck KGaA. The working dilution for uPAR, Ets-1 and FoxM1 antibodies was 1:1,000, 1:500 for uPA antibody and 1:15,000 for GAPDH antibody. The dilution used for both secondary antibodies was $1: 15,000$.

Cell lines and irradiation. The human cervical carcinoma cell lines SiHa (HPV16-positive), HeLa (HPV18-positive) and C33A (HPV-negative) were purchased from the American Type Culture Collection and maintained in DMEM medium supplemented with $10 \%$ fetal bovine serum (Thermo Fisher Scientific, Inc.), $100 \mathrm{U} / \mathrm{ml}$ penicillin, and $100 \mathrm{mg} / \mathrm{ml}$ streptomycin in a humidified incubator at $37^{\circ} \mathrm{C}\left(5 \% \mathrm{CO}_{2}\right)$. When exponentially proliferating cells in culture dishes reached $70-80 \%$ confluence, they were exposed at room temperature to 5 Gray ionizing radiation (6 MV) generated using a linear accelerator (Varian Medical Systems, Inc.); source-to-surface distance, $100 \mathrm{~cm}$; field size $=25 \times 25 \mathrm{~cm}^{2}$. The sham-irradiated cell lysates in Fig. 1 were collected at $24 \mathrm{~h}$ after irradiation. Irradiated cell lysates were collected at 4, 8, 16, 24 and $48 \mathrm{~h}$ after irradiation and subjected to immunoblotting.

Immunoblotting. Whole cell lysates from sham and irradiated cell lines were prepared using RIPA cell lysis buffer were briefly sonicated, at $20 \mathrm{kHz}$ on ice for $30 \mathrm{sec}$, using an ultrasonic sonicator (Thermo Fisher Scientific, Inc.). Protein concentrations were quantified using the bicinchoninic acid (BCA) method. Next, the proteins in the lysates were separated using 10\% gel SDS-PAGE electrophoresis and then electrophoretically transferred onto nitrocellulose membranes, which were probed with the aforementioned antibodies listed above at $4^{\circ} \mathrm{C}$ overnight. GAPDH served as a loading control. Immunocomplexes were detected using secondary antibodies conjugated to horseradish peroxidase for $1 \mathrm{~h}$ at room temperature, and a western blot imaging system (Synoptics Ltd) that employs ECL (Immobilon Forte Western HRP substrate; Merck KGaA) was used to visualize the bands. Densitometry was determined using Image J version $1.53 \mathrm{~g}$ (National Institutes of Health). Immunoblotting was performed in triplicate.

Patients and sample preparation. Patients diagnosed with cervical cancer $(n=153)$ who underwent initial external beam radiation therapy (EBRT) between April 2014 and August 2017 at the Department of Radiation Oncology, Chulabhorn Hospital (Bangkok, Thailand), were considered for inclusion in the present study. The inclusion criteria were as follows: i) Patients pathologically diagnosed with cervical cancer [stages IB-IVA according to the International Federation of Gynecology and Obstetrics (FIGO) 2009] (21), ii) tissue specimens collected at baseline (before treatment with EBRT) and during radiotherapy (before 1st brachytherapy), and iii) clinical data available at initial diagnosis. The exclusion criteria were incomplete sample collection and inadequate amount of tissue sample. The inclusion criteria were met by 72 patients who were included in the data analyses. The primary outcomes of the study were 5-year disease-free survival rate (DFS) and 5-year overall survival rate (OS), defined as the date of radiation therapy until April 2020. DFS refers to patients who survived without signs or recurrence of cervical cancer, and OS refers to those who survived until April 2020. The follow-up was performed at the Department of Radiation Oncology, Chulabhorn Hospital. The patients were followed-up every 3 months after the completion of treatment in the first 2 years, every 4 months in year 3-4 and every 6 months thereafter.

Tumor samples and ELISAs. Cervical tumor biopsies were obtained from patients with their informed consent before their first radiation treatment and during the 16th to 22nd fractions of EBRT at the conventional dose of $2 \mathrm{~Gy}$ per fraction, before the first brachytherapy session. Tumor tissue samples were stored at $-80^{\circ} \mathrm{C}$ and then lysed with RIPA lysis buffer and sonicated on ice at $40 \mathrm{kHz}$ for one minute each. ELISAs of uPA and uPAR levels were performed using human UPA and UPAR kits (cat. nos. ab119611 and ab119612, respectively) in accordance with the manufacturer's instructions (Abcam). Color intensity at $450 \mathrm{~nm}$ was determined using an EnSight multimode plate reader (PerkinElmer, Inc.). Each ELISA reaction included $40 \mu \mathrm{g}$ of tissue lysate. The concentrations of uPA and uPAR were calculated according to standard curves. An increase of $\mathrm{uPA}$ and $\mathrm{UPAR} \geq 1.0 \mathrm{ng}$ per $40 \mu \mathrm{g}$ of total protein of irradiated vs pretreatment tissues was defined as increased expression, and a reduction of uPA and uPAR by $\geq 1.0 \mathrm{ng}$ per $40 \mu \mathrm{g}$ of total protein was defined as decreased expression. ELISAs were 
A
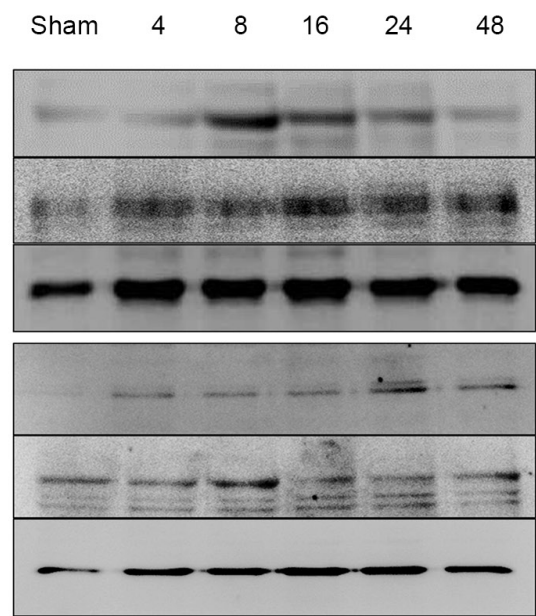

B

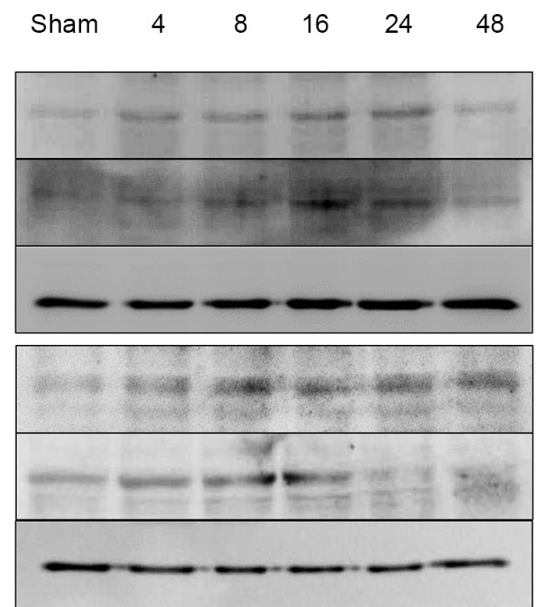

C

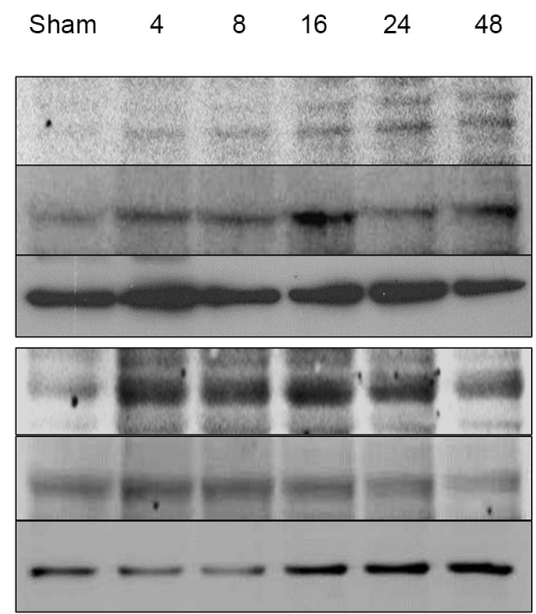

Time post-IR (5Gy, h)

UPA

UPAR

GAPDH

Ets-1

FoxM1

GAPDH

Time post-IR $(5 \mathrm{G}, \mathrm{h})$

UPA

UPAR

GAPDH

Ets-1

FoxM1

GAPDH

Time post-IR (5Gy, h)

UPA

UPAR

GAPDH

Ets-1

FoxM1

GAPDH
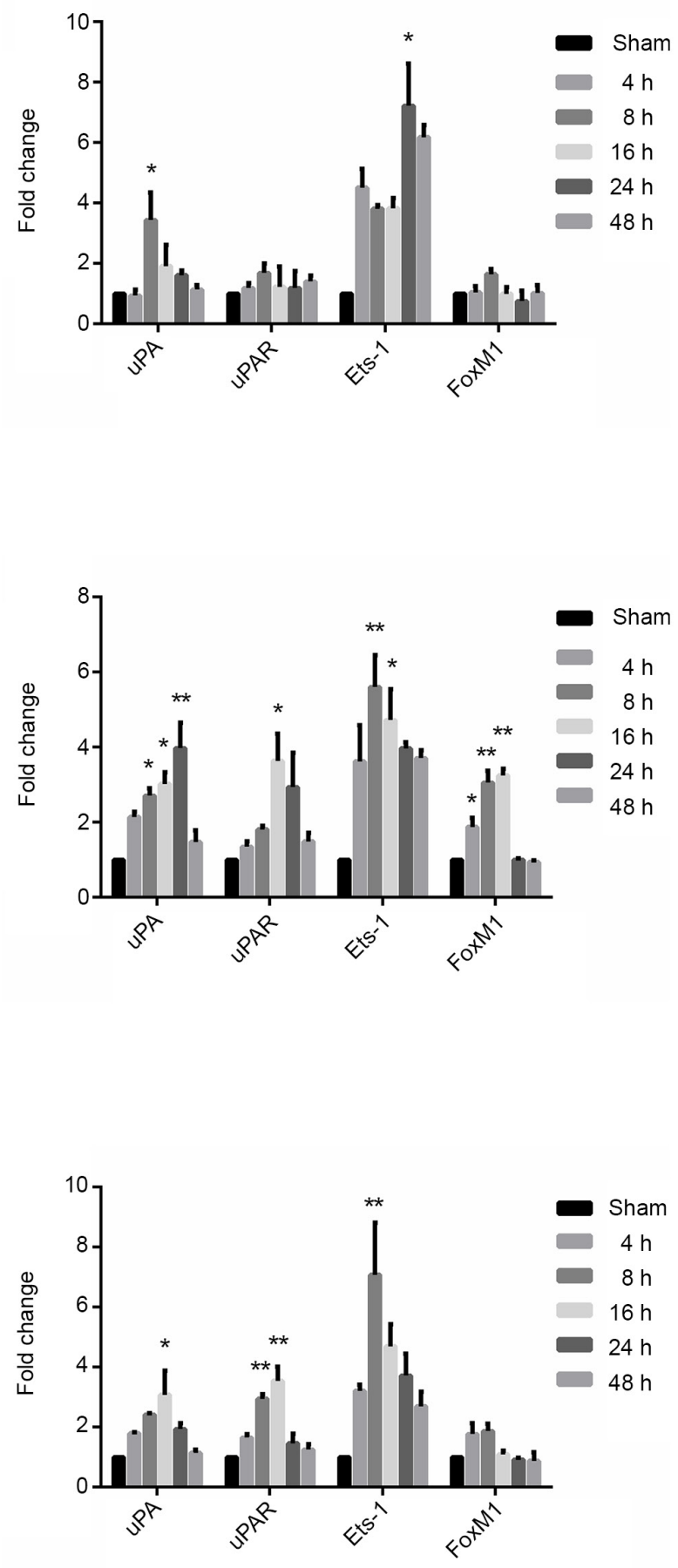

Figure 1. Immunoblotting analysis of uPA, uPAR and their target transcription factors after 5 Gy irradiation of (A) SiHa, (B) HeLa and (C) C33A cells. ${ }^{*} \mathrm{P}<0.05$ and ${ }^{* *} \mathrm{P}<0.01$ vs sham. uPA, urokinase plasminogen activator; uPAR, urokinase plasminogen activator receptor; FoxM1, forkhead box protein M1; IR, irradiation.

performed in duplicate. The median levels for uPA and UPAR pretreatment before and after completion of EBRT were used as cut-off values for survival analysis. For uPA, the median values were $2.64 \mathrm{ng}$ and $1.79 \mathrm{ng} / 40 \mu \mathrm{g}$ of tissue sample protein for pretreatment and after EBRT, respectively. For uPAR, the median values were $1.04 \mathrm{ng}$ and $1.36 \mathrm{ng} / 40 \mu \mathrm{g}$ of tissue sample protein for pretreatment and after EBRT, respectively.
Statistical analysis. Continuous variables are presented the median and range, and categorical variables are shown as frequencies and percentages (unless otherwise shown). Statistical comparisons between continuous variables were undertaken using one-way ANOVA with Tukey's post hoc test. A paired t-test was used to compare protein expression levels. DFS and OS were evaluated using the Kaplan-Meier 
method with a log-rank test. The Cox proportional hazards model was used for univariate analysis of covariates as well as for multivariate analysis. $\mathrm{P}<0.05$ was considered to indicate a statistically significant difference. All statistical analyses were performed using STATA version 12.1 software (StataCorp LLC).

\section{Results}

Exposure to ionizing radiation upregulates $u P A$ expression in cervical cancer cell lines. To determine whether the expression of UPA and its receptor UPAR were regulated by ionizing radiation, the human cervical cancer cell lines were irradiated (5 Gy) as follows: SiHa (HPV16-Positive), HeLa (HPV18-positive) and C33A (HPV-negative). As shown in Fig. 1, immunoblotting analysis revealed that the expression of UPA and UPAR was increased in irradiated cells after 8-24 h. uPA was significantly increased at $8 \mathrm{~h}, 8-24 \mathrm{~h}$ and $16 \mathrm{~h}$ post-irradiation for SiHa, HeLa and C33A cells, respectively. uPAR expression levels were significantly upregulated at $8 \mathrm{~h}$ and 8-16 h after irradiation in HeLa and C33A cells but not in SiHa cells. Radiation exposure also generally increased the expression level of uPA-regulated transcription factor Ets-1 in all three cell lines after 4-48 h, but only significantly upregulated the protein after $24 \mathrm{~h}, 8-16 \mathrm{~h}$ and $8 \mathrm{~h}$ for SiHa, HeLa and C33A cells, respectively. Furthermore, the uPAR-regulated transcription factor FoxM1 was significantly upregulated by ionizing radiation in HeLa cells after 8-16 h, but not in the other cell lines.

Patient characteristics and responses to treatment. It was next determined whether the expression of UPA and UPAR was upregulated in patients receiving radiotherapy. Patient demographic data are shown in Table I. Their mean age was 53.5 years (range, 25-85 years), $73.61 \%$ had squamous cell carcinoma (38.89\% with FIGO Stage IIB). In total, $\sim 67 \%$ of patients were HPV-positive, $76.39 \%$ received concurrent chemoradiotherapy followed by intracavitary radiotherapy, $65.28 \%$ were administered cisplatin-based chemotherapy and $16.67 \%$ were administered carboplatin. The patients received a median dose of 89.45 Gy (equivalent dose $_{2}$ ) with median radiation treatment for 43 days.

All patients were treated and regularly underwent follow-up examinations. As shown in Table II, 70.8\% experienced a complete response (undetectable tumors) and the median survival time was 35 months (range, 2-60 months). Cervical tumor biopsies were performed during their 16th to 22nd fractions of pelvic irradiation at the conventional dose of 2 Gy per fraction, before the first brachytherapy session. The uPA and UPAR levels remained largely unchanged (47.22 and $79.17 \%$ of the patients, respectively), whereas radiotherapy led to an increase in UPA and uPAR levels in 16.67 and $18.06 \%$ of patients, respectively. Furthermore, uPA and UPAR levels in 36.11 and $2.78 \%$ decreased, respectively. For uPA, 34 patients had no change in expression, 26 patients had decreased expression and 12 patients had increased expression. For uPAR, 57 patients had no change in expression, two patients had decreased expression and 13 patients had increased expression. These results showed that uPA expression generally decreased after EBRT $(\mathrm{P}=0.02)$, although uPAR expression increased
Table I. Characteristics of 72 patients with cervical cancer.

\begin{tabular}{|c|c|}
\hline Variables & Value \\
\hline Age at diagnosis, median (range) years & $53.5(25-85)$ \\
\hline \multicolumn{2}{|l|}{ Histological type, n (\%) } \\
\hline Squamous cell carcinoma & $53(73.61)$ \\
\hline Neuroendocrine carcinoma & $4(5.55)$ \\
\hline Adenosquamous carcinoma & $12(16.67)$ \\
\hline Adenocarcinoma & $3(4.17)$ \\
\hline \multicolumn{2}{|l|}{ FIGO staging, n (\%) } \\
\hline IB2- IIA & $17(23.61)$ \\
\hline IIB & $28(38.89)$ \\
\hline IIIA-IIIB & $25(34.72)$ \\
\hline IVA & $2(2.78)$ \\
\hline \multicolumn{2}{|l|}{ HPV status, n $(\%)$} \\
\hline Negative & $8(11.11)$ \\
\hline Positive & $48(66.67)$ \\
\hline Not available & $16(22.22)$ \\
\hline \multicolumn{2}{|l|}{ Treatment, n (\%) } \\
\hline CCRT + ICRT & $55(76.39)$ \\
\hline CCRT + ICRT + Adjuvant treatment & $13(18.06)$ \\
\hline $\mathrm{EBRT}+\mathrm{ICRT}$ & $3(4.17)$ \\
\hline EBRT + ICRT + Adjuvant treatment & $1(1.39)$ \\
\hline \multicolumn{2}{|l|}{ Chemotherapy regimen, $\mathrm{n}(\%)$} \\
\hline No chemotherapy & $4(5.56)$ \\
\hline Cisplatin & $47(65.28)$ \\
\hline Carboplatin & $12(16.67)$ \\
\hline Combination & $9(12.50)$ \\
\hline $\begin{array}{l}\text { Number of days for radiation treatments, } \\
\text { median (range) days }\end{array}$ & $43(12-87)$ \\
\hline $\begin{array}{l}\text { EBRT + Brachytherapy, median } \\
\text { (range), Gy }\end{array}$ & $89.45(56-99.6$ \\
\hline ICRT course fractions, range, days & $3-5$ \\
\hline Cycle of chemotherapy, range, cycles & $0-7$ \\
\hline \multicolumn{2}{|l|}{ Technique of EBRT, n (\%) } \\
\hline $\mathrm{AP} / \mathrm{PA}$ & $21(29.17)$ \\
\hline 4-field box & $44(61.11)$ \\
\hline VMAT & $2(2.78)$ \\
\hline Combination & $5(6.94)$ \\
\hline
\end{tabular}

CCRT, concurrent radiotherapy; ICRT, intracavitary radiotherapy; EBRT, external beam radiation therapy; AP/PA, anterior-posterior/posterior-anterior; VMAT, volumetric modulated arc therapy; EQD, equivalent dose; FIGO, Federation of Gynecology and Obstetrics.

$(\mathrm{P}=0.001)$ (Fig. 2). Notably, the changes in uPA and uPAR expression in HPV-positive patients followed a similar trend (Fig. S1), suggesting that HPV plays a role in the regulation of the expression of UPA and UPAR.

Factors influencing therapeutic outcome. The results shown in Table III indicated that treatment response was a major predictive factor of outcomes. Among the 72 patients, 13 died, 59 survived and four experienced recurrence (Table II). The 
Table II. Responses to treatment of 72 patients with cervical cancer who underwent radiation therapy.

\begin{tabular}{lc}
\hline Variables & Value \\
\hline Patient treatment outcome, n (\%) & \\
Survived & $59(81.94)$ \\
Deceased & $13(18.06)$ \\
Experienced recurrence & $4(5.56)$ \\
Treatment response, n (\%) & \\
Complete response & $51(70.83)$ \\
Partial response & $8(11.11)$ \\
Progressive disease & $6(8.33)$ \\
N/A & $7(9.72)$ \\
uPA levels, n (\%) & \\
No change & $34(47.22)$ \\
Decreased & $26(36.11)$ \\
Increased & $12(16.67)$ \\
uPAR levels, n (\%) & \\
No change & $57(79.17)$ \\
Decreased & $2(2.78)$ \\
Increased & $13(18.06)$ \\
Overall survival time, median (range) months & $35(2-60)$ \\
\end{tabular}

uPA, urokinase plasminogen activator; uPAR, urokinase plasminogen activator receptor.

DFS of patients with progressive disease was significantly shorter (HR, 56.59; 95\% CI, 13.45-238.09) as well as their OS [HR, 13.41; 95\% CI, 1.17-153.07 (univariate analysis); and HR, 47.16; 95\% CI, 3.11-714.63 (multivariate analysis)]. The patients with a partial response to therapy experienced shorter OS (HR, 7.22; 95\% CI, 1.17-44.73).

Although the level of uPA expression was not significantly associated with OS (HR, 2.68; 95\% CI, 0.71-10.06), increased uPAR expression was predictive. Univariate and multivariate analyses indicated that the upregulation of uPAR levels in cervical tumor tissue may serve as a prognostic factor for predicting OS [HR, 3.65; 95\% CI, 1.18-11.30 (univariate analysis); and HR, 6.72; 95\% CI, 1.71-26.37 (multivariate analysis)]. The data shown in Fig. 3 support the conclusion that increased UPAR expression may serve as a prognostic factor for OS but not DFS. Neither the absolute levels of expression nor the differences of either protein were a significant predictor of DFS. Together, these findings supported the conclusion that the levels of UPA and UPAR before and after EBRT were not significantly associated with DFS or OS (Figs. S2-5).

\section{Discussion}

Irradiation of tumor cells activates numerous genes encoding products that contribute to tumor invasion and metastasis, which frequently shortens survival time (22). For example, irradiation activates uPA and UPAR expression and causes meningiomas to grow in vivo (23). Consistent with these findings, the present in vitro data showed that uPA and UPAR expression was upregulated by radiation, which may be explained by their transcriptional activation by Ets-1 and FoxM1, respectively $(10,24)$. Radiation-induced activation of NF-KB activation may account for upregulation of uPA and uPAR as well $(25,26)$. In contrast to this, the current data acquired using tumor samples differed from these results regarding UPA expression, particularly because the protocol mimicked that employed in the clinic (five fractions per week). This may be attributed to the presence of HPV, which confers radiosensitivity (27), and patients who were HPV-positive appeared to have reduced uPA levels but enhanced UPAR levels after receiving radiotherapy. The HPV E6 oncoprotein targets and reduces the expression of microRNA (miR)(miR-23b) and miR-34a, which negatively regulates uPA expression $(18,28,29)$. These miRs are induced in irradiated tumor tissue samples $(30,31)$. Thus, fractionated irradiation may enhance miR-23b and miR-34a expression and subsequently downregulate uPA expression.

HPV status and genotypes may affect the outcome of treatment because the prognosis of patients who are HPV-negative with cervical cancer is worse compared with those with HPV infection (32). Furthermore, HPV titers may predict the radiation response of cervical tumors (33). Similarly, HPV-positive head and neck tumors are more sensitive to conventional radiation or chemo- therapies $(34,35)$. Higher radiosensitivity is caused by defective DNA damage repair, particularly due to double-stand breaks (36). An improved understanding of the interactions between HPV and therapeutics will hopefully contribute to the development of optimal individualized treatments. Another plausible reason for the downregulation of uPA after EBRT is activation of c-Myc by radiation $(37,38)$.

Although the expression of UPA and PAI-1 in cervical tumor tissue was previously suggested to serve as a prognostic marker for stage II cervical cancer (19), the induced expression of uPA in response to radiotherapy was not significantly related to a patient DFS or OS in the present study. Furthermore, the level of uPA in cervical tumor tissue has little prognostic value (39). Nevertheless, evidence indicates that the urokinase system is closely associated with stem cell-like properties of numerous types of cancer cell, such as activated STAT3 in lung cancer and CD24/CD $44^{+}$breast cancer (40). Accumulating evidence also indicates an association between the urokinase system and EMT, involving tumor cell depolarization into a mesenchymal phenotype characterized by high motility and enhanced resistance to cell death (41). Inhibition or downregulation of uPA, uPAR or both, inhibits hypoxia-mediated EMT (42). Additionally, uPA is known for its functions in tumor cell invasion, its involvement in TGF- $\beta$ activation as well as its participation in EMT (43). Thus, UPA may contribute to the formation of distant metastasis and the characteristics of the tumor microenvironment, which further studies should be looking into.

The present study demonstrated that uPAR expression may serve to predict prognosis because of its contributions to metastasis and cell survival through expression of mesenchymal genes (44). Furthermore, uPAR affects DNA damage repair through activation of Chk1 and Rad51 and contributes to multidrug resistance mechanisms through its interaction with proteins such as vitronectin, integrins and EGFR $(45,46)$. The current study further highlights that increased expression of uPAR in 
Table III. Univariate and multivariate Cox proportional hazard regression analyses of DFS and OS.

\begin{tabular}{|c|c|c|c|c|c|c|}
\hline \multirow[b]{3}{*}{ Variable } & \multirow{2}{*}{\multicolumn{2}{|c|}{$\frac{\text { DFS }}{\text { Univariate analysis }}$}} & \multicolumn{4}{|c|}{ OS } \\
\hline & & & \multicolumn{2}{|c|}{ Univariate analysis } & \multicolumn{2}{|c|}{ Multivariate analysis } \\
\hline & $\mathrm{HR}(95 \% \mathrm{CI})$ & P-value & $\mathrm{HR}(95 \% \mathrm{CI})$ & P-value & $\mathrm{HR}(95 \% \mathrm{CI})$ & P-value \\
\hline \multicolumn{7}{|l|}{ Age, years } \\
\hline$\leq 50$ & Ref. & - & Ref. & - & & \\
\hline$>50$ & $0.58(0.22-1.49)$ & 0.256 & $0.81(0.27-2.42)$ & 0.707 & & \\
\hline \multicolumn{7}{|l|}{ FIGO stage } \\
\hline IB2- IIA & Ref. & - & Ref. & - & & \\
\hline IIB & $2.25(0.47-10.83)$ & 0.312 & $1.48(0.29-7.66)$ & 0.637 & & \\
\hline IIIA-IIIB & $3.25(0.67-15.70)$ & 0.142 & $2.93(0.59-14.62)$ & 0.190 & & \\
\hline IVA & $6.37(0.58-70.55)$ & 0.131 & 0.00 & $>0.999$ & & \\
\hline \multicolumn{7}{|l|}{ Histological type } \\
\hline Squamous cell carcinoma & Ref. & - & Ref. & & & \\
\hline Neuroendocrine carcinoma & $1.23(0.16-9.59)$ & 0.840 & 0.00 & $>0.999$ & & \\
\hline Other & $1.66(0.57-4.78)$ & 0.351 & $1.70(0.52-5.55)$ & 0.379 & & \\
\hline Treatment response & & & & & Ref. & - \\
\hline Complete & Ref. & - & Ref. & - & $6.07(0.90-41.10)$ & 0.064 \\
\hline Partial & $2.41(0.50-11.66)$ & 0.273 & $7.22(1.17-44.73)$ & 0.034 & $47.16(3.11-714.63)$ & 0.005 \\
\hline Progressive disease & $56.59(13.45-238.09)$ & $<0.001$ & $13.41(1.17-153.07)$ & 0.037 & $58.58(11.47-299.34$ & $<0.001$ \\
\hline N/A & $3.68(0.76-17.92)$ & 0.107 & $40.97(9.27-181.04)$ & $<0.001$ & & \\
\hline \multicolumn{7}{|l|}{ uPA levels } \\
\hline No change & Ref. & - & Ref. & - & & \\
\hline Decreased & $0.54(0.16-1.74)$ & 0.299 & $0.93(0.25-3.48)$ & 0.918 & & \\
\hline Increased & $1.39(0.43-4.53)$ & 0.585 & $2.68(0.71-10.06)$ & 0.145 & & \\
\hline \multicolumn{7}{|l|}{ uPAR levels } \\
\hline No change & Ref. & - & Ref. & - & Ref. & - \\
\hline Decreased & $2.32(0.30-17.76)$ & 0.419 & 0.00 & $>0.999$ & 0.00 & $>0.999$ \\
\hline Increased & $1.12(0.32-3.96)$ & 0.855 & $3.65(1.18-11.30)$ & 0.025 & $6.72(1.71-26.37)$ & 0.006 \\
\hline
\end{tabular}

Comparisons made against Ref. group. HR, hazard ratio; CI, confidence interval; Ref., reference; DFS, disease-free survival; OS, overall survival.
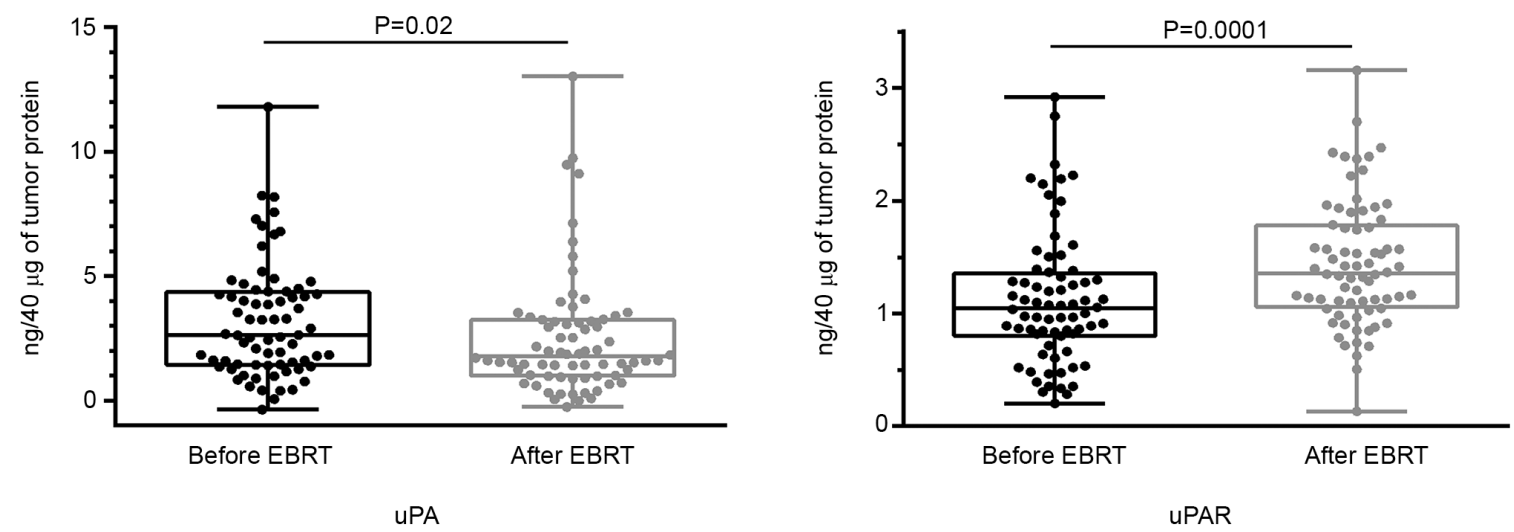

Figure 2. ELISAs of the levels of uPA and uPAR in tumor tissue samples collected from patients with cervical cancer before and after EBRT. uPA, urokinase plasminogen activator; uPAR, urokinase plasminogen activator receptor; EBRT, external beam radiation therapy.

cervical tumor tissue, particularly during treatment, may serve as a prognostic factor that predicts survival. In accordance with the present findings, circulating soluble uPAR serves as a marker for diagnosis and prognosis of cervical cancer (47). Thus, uPAR should be considered a marker for predicting the prognosis of patients with cervical cancer as serum levels of UPAR are 
A
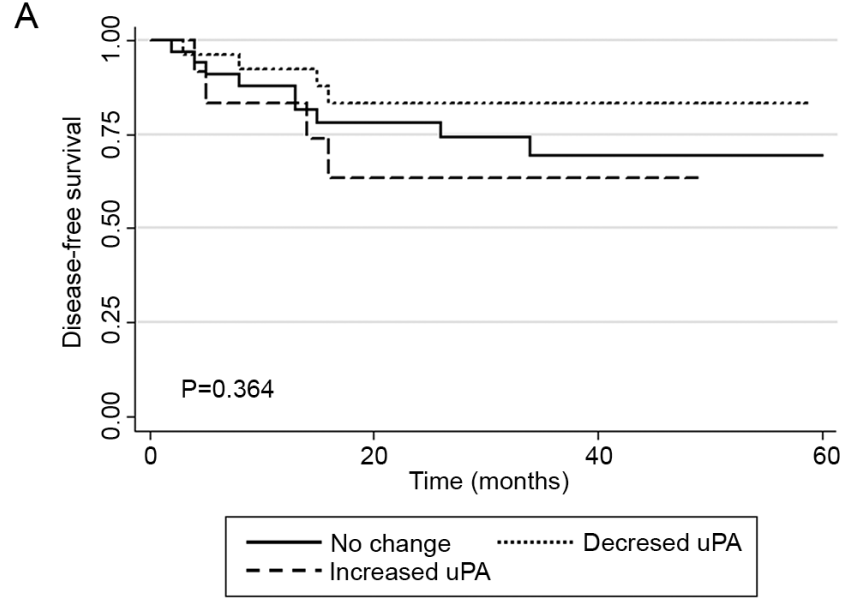

C

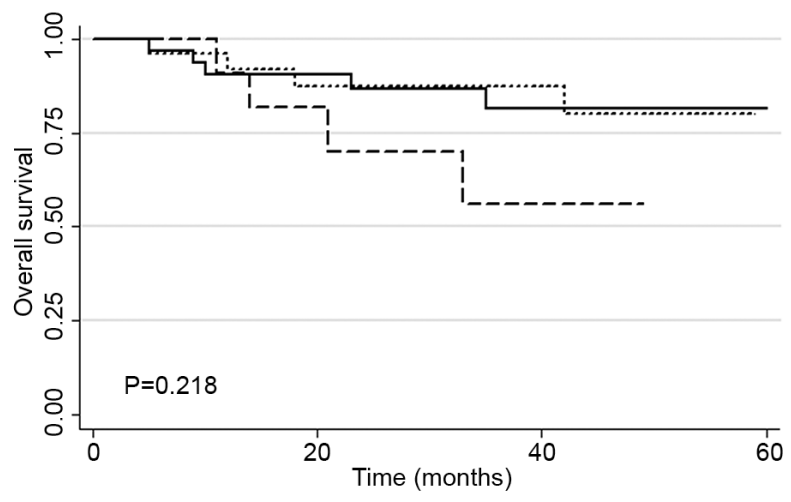

No change
--- - Increased u...... Decresed uPA
B

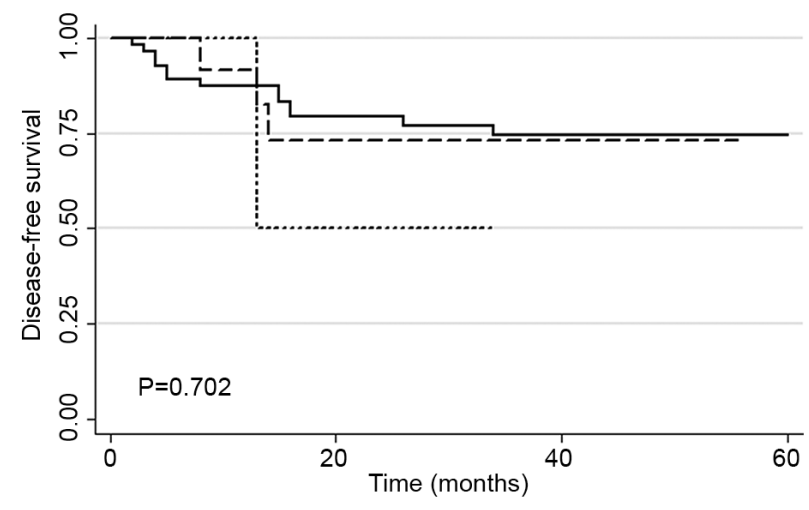

\begin{tabular}{|l|l|}
\hline No change $\quad$ N......... Decresed uPAR \\
\hline-- Increased uPAR
\end{tabular}

D

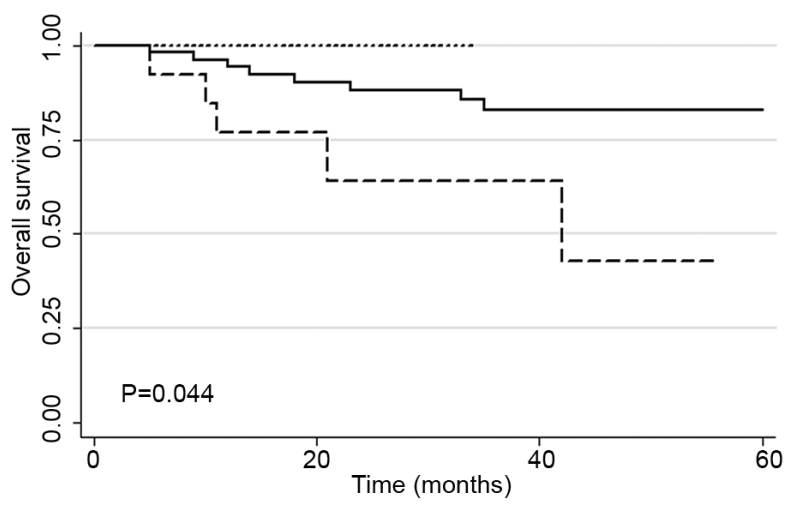

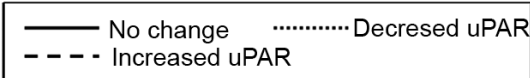

Figure 3. Kaplan-Meier analysis of disease-free survival of patients with no change, decreased, or increased (A) uPA levels or (B) uPAR levels and overall survival of the patients with no change, decreased or increased (C) uPA levels and (D) uPAR levels. uPA, urokinase plasminogen activator; uPAR, urokinase plasminogen activator receptor.

associated with treatment outcomes of patients with breast, colon, rectal and ovarian cancer $(48,49)$. Acquiring post-EBRT tissue biopsies is relatively invasive, and future studies should focus on determining whether less invasive assays, such as those that measure serum UPAR, are as sensitive and specific as those that measure tissue uPAR. The lack of serum UPA and UPAR level measurements is a potential limitation of the current study. In the meantime, for those patients who poorly respond to radiotherapy, the authors hypothesize that post-EBRT biopsies can be used to determine the levels of uPAR as well as those of other prognostic markers. UPAR should therefore be considered to select the most effective treatment strategy.

The current study reported that the expression of uPA and UPAR was unsuitable as a prognostic marker for patients with cervical cancer, which may be explained by the proteolytic activities of UPA and UPAR that are often associated with tumor cell migration and metastasis, which then contributed to a radioresistant phenotype (50). In contrast to this, uPAR expression may reflect the induction of the epithelial mesenchymal transition (EMT) upon activation of the ERK1/2 signaling pathway (51). Nevertheless, the results were based on the limited availability of number of patients $(n=72)$ who underwent EBRT and were voluntary to participate in the study. Several other factors should be considered when comparing the results from different studies, such as genotype and HPV status. A larger number of subjects will therefore be required to validate the present findings.

With the emergence of high-throughput sequencing and advances in bioinformatics, computational methods are used to analyze genotypes, transcriptomes, proteomes and metabolomes to identify specific diagnostic and prognostic markers of cancer (52). For example, a mutation profiling study found that mutations in the gene encoding fibroblast growth factor receptor are associated with poor progression-free survival rate in patients with cervical cancer (53). System biology approaches may therefore prove useful and provide new directions in the pursuit of identifying new markers for cancer diagnosis and therapy.

In summary, although the expression levels of uPA and UPAR were altered by irradiation, only the upregulation in uPAR expression in tissue samples predicted the OS of patients with cervical cancer. Targeting uPAR expressed in cervical tumors may therefore contribute to more effective therapeutic strategies.

\section{Acknowledgments}

The authors would like to thank Mr Chirasak Khamfongkhruea, Mr Saengutid Thongsawad, Mr Kittipol Dachaworakul and Dr Nuttavut Kantathavorn (all Faculty of 
Medicine and Public Health, Chulabhorn Royal Academy) for assistance in conducting the study, Dr Kamonwan Soonklang (Department of Research Innovation and International Relations, HRH Princess Chulabhorn College of Medical Science) for assistance in conducting the statistical analyses and Dr Steven Tronick (Edanz Group) for editing a draft of this manuscript.

\section{Funding}

This study was supported by Chulabhorn Royal Academy granted to KL.

\section{Availability of data and materials}

The datasets used and/or analyzed during the current study are available from the corresponding author upon reasonable request.

\section{Authors' contributions}

DN conceptualized the study and wrote the manuscript. DN, $\mathrm{SC}$ and KL designed the study. DN and PC performed the in vitro experiments and collected the data. $\mathrm{PC}, \mathrm{SB}$ and $\mathrm{SC}$ collected and evaluated the clinical data and conducted the statistical analyses. DN and SC confirmed the authenticity of the raw data. SC and KL supervised the study and revised the manuscript. All authors read and approved the final manuscript.

\section{Ethics approval and consent to participate}

The Committee on Human Rights Related to Research Involving Human Subjects, Chulabhorn Research Institute, (Bangkok, Thailand) approved the study (approval no. 04/2557). Written informed consent was provided by each patient.

\section{Patient consent for publication}

Not applicable.

\section{Competing interests}

The authors declare that they have no competing interests.

\section{References}

1. Gatenby RA, Silva AS, Gillies RJ and Frieden BR: Adaptive therapy. Cancer Res 69: 4894-4903, 2009.

2. Ahmed KM and Li JJ: NF-kappa B-mediated adaptive resistance to ionizing radiation. Free Radic Biol Med 44: 1-13, 2008.

3. Roos WP, Thomas AD and Kaina B: DNA damage and the balance between survival and death in cancer biology. Nat Rev Cancer 16: 20-33, 2016.

4. Duffy MJ, Maguire TM, McDermott EW and O'Higgins N: Urokinase plasminogen activator: A prognostic marker in multiple types of cancer. J Surg Oncol 71: 130-135, 1999.

5. Gonias SL and $\mathrm{Hu} \mathrm{J}$ : Urokinase receptor and resistance to targeted anticancer agents. Front Pharmacol 6: 154, 2015.

6. Mahmood N, Mihalcioiu C and Rabbani SA: Multifaceted role of the urokinase-type plasminogen activator (uPA) and its receptor (uPAR): Diagnostic, prognostic, and therapeutic applications Front Oncol 8: 24, 2018.

7. Ulisse S, Baldini E, Sorrenti S and D'Armiento M: The urokinase plasminogen activator system: A target for anti-cancer therapy. Curr Cancer Drug Targets 9: 32-71, 2009.
8. Watabe T, Yoshida K, Shindoh M, Kaya M, Fujikawa K, Sato H, Seiki M, Ishii S and Fujinaga K: The Ets-1 and Ets-2 transcription factors activate the promoters for invasion-associated urokinase and collagenase genes in response to epidermal growth factor. Int J Cancer 77: 128-137, 1998.

9. Lund IK, Nielsen BS, Almholt K, Rono B, Hald A, Illemann M, Green KA, Christensen IJ, Romer J and Lund LR: Concomitant lack of MMP9 and uPA disturbs physiological tissue remodeling. Dev Biol 358: 56-67, 2011.

10. Li D, Wei P, Peng Z, Huang C, Tang H, Jia Z, Cui J, Le X, Huang S and Xie K: The critical role of dysregulated FOXM1-PLAUR signaling in human colon cancer progression and metastasis. Clin Cancer Res 19: 62-72, 2013.

11. Blasi F and Sidenius N: The urokinase receptor: Focused cell surface proteolysis, cell adhesion and signaling. FEBS Lett 584: 1923-1930, 2010.

12. Kugaevskaya EV, Gureeva TA, Timoshenko OS and Solovyeva NI: The urokinase-type plasminogen activator system and its role in tumor progression. Biomed Khim 64: 472-486, 2018.

13. Su SC, Lin CW, Yang WE, Fan WL and Yang SF: The urokinase-type plasminogen activator (uPA) system as a biomarker and therapeutic target in human malignancies. Expert Opin Ther Targets 20: 551-566, 2016.

14. Harbeck N, Schmitt M, Meisner C, Friedel C, Untch M, Schmidt M, Sweep CG, Lisboa BW, Lux MP, Beck T, et al: Ten-year analysis of the prospective multicentre Chemo-NO trial validates American society of clinical oncology (ASCO)-recommended biomarkers uPA and PAI-1 for therapy decision making in node-negative breast cancer patients. Eur J Cancer 49: 1825-1835, 2013.

15. Small W Jr, Bacon MA, Bajaj A, Chuang LT, Fisher BJ, Harkenrider MM, Jhingran A, Kitchener HC, Mileshkin LR, Viswanathan AN and Gaffney DK: Cervical cancer: A global health crisis. Cancer 123: 2404-2412, 2017.

16. de Sanjose S, Quint WG, Alemany L, Geraets DT, Klaustermeier JE, Lloveras B, Tous S, Felix A, Bravo LE, Shin HR, et al: Human papillomavirus genotype attribution in invasive cervical cancer: A retrospective cross-sectional worldwide study. Lancet Oncol 11: 1048-1056, 2010.

17. Machalek DA, Roberts JM, Garland SM, Thurloe J, Richards A, Chambers I, Sivertsen T and Farnsworth A: Routine cervical screening by primary HPV testing: Early findings in the renewed National cervical screening program. Med J Aust 211: 113-119, 2019.

18. Au Yeung CL, Tsang TY, Yau PL and Kwok TT: Human papillomavirus type 16 E6 induces cervical cancer cell migration through the $\mathrm{p} 53 / \mathrm{microRNA}-23 \mathrm{~b} /$ urokinase-type plasminogen activator pathway. Oncogene 30: 2401-2410, 2011.

19. Kobayashi H, Fujishiro $S$ and Terao T: Impact of urokinase-type plasminogen activator and its inhibitor type 1 on prognosis in cervical cancer of the uterus. Cancer Res 54: 6539-6548, 1994.

20. Sugimura M, Kobayashi H, Kanayama N and Terao T: Clinical significance of urokinase-type plasminogen activator (uPA) in invasive cervical cancer of the uterus. Gynecol Oncol 46: 330-336, 1992.

21. Pecorelli S: Revised FIGO staging for carcinoma of the vulva, cervix, and endometrium. Int J Gynaecol Obstet 105: 103-104, 2009.

22. Lee SY, Jeong EK, Ju MK, Jeon HM, Kim MY, Kim CH, Park HG, Han SI and Kang HS: Induction of metastasis, cancer stem cell phenotype, and oncogenic metabolism in cancer cells by ionizing radiation. Mol Cancer 16: 10, 2017.

23. Kargiotis O, Chetty C, Gogineni V, Gondi CS, Pulukuri SM, Kyritsis AP, Gujrati M, Klopfenstein JD, Dinh DH and Rao JS: uPA/uPAR downregulation inhibits radiation-induced migration, invasion and angiogenesis in IOMM-Lee meningioma cells and decreases tumor growth in vivo. Int J Oncol 33: 937-947, 2008.

24. Nakada M, Yamashita J, Okada Y and Sato H: Ets-1 positively regulates expression of urokinase-type plasminogen activator (uPA) and invasiveness of astrocytic tumors. J Neuropathol Exp Neurol 58: 329-334, 1999.

25. Qu M, Yu J, Liu H, Ren Y, Ma C, Bu X and Lan Q: The candidate tumor suppressor gene SLC8A2 inhibits invasion, angiogenesis and growth of glioblastoma. Mol Cells 40: 761-772, 2017.

26. Reuning U, Wilhelm O, Nishiguchi T, Guerrini L, Blasi F, Graeff $\mathrm{H}$ and Schmitt M: Inhibition of NF-kappa B-Rel A expression by antisense oligodeoxynucleotides suppresses synthesis of urokinase-type plasminogen activator (uPA) but not its inhibitor PAI-1. Nucleic Acids Res 23: 3887-3893, 1995. 
27. Mesher D, Cuschieri K, Hibbitts S, Jamison J, Sargent A Pollock KG, Powell N, Wilson R, McCall F, Fiander A and Soldan K: Type-specific HPV prevalence in invasive cervical cancer in the UK prior to national HPV immunisation programme: Baseline for monitoring the effects of immunisation. J Clin Pathol 68: 135-140, 2015.

28. Pang RT, Leung CO, Ye TM, Liu W, Chiu PC, Lam KK, Lee KF and Yeung WS: MicroRNA-34a suppresses invasion through downregulation of Notch1 and Jagged1 in cervical carcinoma and choriocarcinoma cells. Carcinogenesis 31 : 1037-1044, 2010.

29. Wang X, Wang HK, McCoy JP, Banerjee NS, Rader JS, Broker TR, Meyers C, Chow LT and Zheng ZM: Oncogenic HPV infection interrupts the expression of tumor-suppressive miR-34a through viral oncoprotein E6. RNA 15: 637-647, 2009.

30. Lacombe $\mathrm{J}$ and Zenhausern F: Emergence of miR-34a in radiation therapy. Crit Rev Oncol Hematol 109: 69-78, 2017.

31. Li B, Sun M, Gao F, Liu W, Yang Y, Liu H, Cheng Y, Liu C and Cai J: Up-regulated expression of miR-23a/b targeted the pro-apoptotic Fas in radiation-induced thymic lymphoma. Cell Physiol Biochem 32: 1729-1740, 2013.

32. Harima Y, Sawada S, Nagata K, Sougawa M and Ohnishi T: Human papilloma virus (HPV) DNA associated with prognosis of cervical cancer after radiotherapy. Int J Radiat Oncol Biol Phys 52: 1345-1351, 2002.

33. Datta NR, Kumar P, Singh S, Gupta D, Srivastava A and Dhole TN: Does pretreatment human papillomavirus (HPV) titers predict radiation response and survival outcomes in cancer cervix?-A pilot study. Gynecol Oncol 103: 100-105, 2006

34. Gottgens EL, Ostheimer C, Span PN, Bussink J and Hammond EM: HPV, hypoxia and radiation response in head and neck cancer. Br J Radiol 92: 20180047, 2019.

35. Nagel R, Martens-de Kemp SR, Buijze M, Jacobs G, Braakhuis BJ and Brakenhoff RH: Treatment response of HPV-positive and HPV-negative head and neck squamous cell carcinoma cell lines. Oral Oncol 49: 560-566, 2013

36. Rieckmann T, Tribius S, Grob TJ, Meyer F, Busch CJ, Petersen C, Dikomey E and Kriegs M: HNSCC cell lines positive for HPV and p16 possess higher cellular radiosensitivity due to an impaired DSB repair capacity. Radiother Oncol 107: 242-246, 2013.

37. Alfano D, Votta G, Schulze A, Downward J, Caputi M, Stoppelli MP and Iaccarino I: Modulation of cellular migration and survival by c-Myc through the downregulation of urokinase (UPA) and uPA receptor. Mol Cell Biol 30: 1838-1851, 2010.

38. Sawey MJ, Hood AT, Burns FJ and Garte SJ: Activation of c-myc and $\mathrm{c}-\mathrm{K}$-ras oncogenes in primary rat tumors induced by ionizing radiation. Mol Cell Biol 7: 932-935, 1987.

39. Horn LC, Pippig S, Raptis G, Fischer U, Kohler U, Hentschel B and Martin R: Clinical relevance of urokinase-type plasminogen activator and its inhibitor type 1 (PAI-1) in squamous cell carcinoma of the uterine cervix. Aust N Z J Obstet Gynaecol 42 383-386, 2002

40. Jo M, Eastman BM, Webb DL, Stoletov K, Klemke R and Gonias SL: Cell signaling by urokinase-type plasminogen activator receptor induces stem cell-like properties in breast cancer cells. Cancer Res 70: 8948-8958, 2010.
41. Madunic J: The urokinase plasminogen activator system in human cancers: An overview of its prognostic and predictive role. Thromb Haemost 118: 2020-2036, 2018.

42. Gupta R, Chetty C, Bhoopathi P, Lakka S, Mohanam S, Rao JS and Dinh DE: Downregulation of uPA/uPAR inhibits intermittent hypoxia-induced epithelial-mesenchymal transition (EMT) in DAOY and D283 medulloblastoma cells. Int J Oncol 38: 733-744, 2011.

43. Santibanez JF, Obradovic H, Kukolj T and Krstic J: Transforming growth factor- $\beta$, matrix metalloproteinases, and urokinase-type plasminogen activator interaction in the cancer epithelial to mesenchymal transition. Dev Dyn 247: 382-395, 2018.

44. Gilder AS, Natali L, Van Dyk DM, Zalfa C, Banki MA, Pizzo DP, Wang H, Klemke RL, Mantuano E and Gonias SL: The urokinase receptor induces a mesenchymal gene expression signature in glioblastoma cells and promotes tumor cell survival in Neurospheres. Sci Rep 8: 2982, 2018.

45. Narayanaswamy PB, Tkachuk S, Haller H, Dumler I and Kiyan Y: CHK1 and RAD51 activation after DNA damage is regulated via urokinase receptor/TLR4 signaling. Cell Death Dis 7: e2383, 2016.

46. Wang K, Xing ZH, Jiang QW, Yang Y, Huang JR, Yuan ML, Wei MN, Li Y, Wang ST, Liu K and Shi Z: Targeting uPAR by CRISPR/Cas9 system attenuates cancer malignancy and multidrug resistance. Front Oncol 9: 80, 2019.

47. Jing J, Zheng S, Han C, Du L, Guo Y and Wang P: Evaluating the value of uPAR of serum and tissue on patients with cervical cancer. J Clin Lab Anal 26: 16-21, 2012.

48. Duffy MJ and Duggan C: The urokinase plasminogen activator system: A rich source of tumour markers for the individualised management of patients with cancer. Clin Biochem 37: 541-548, 2004.

49. Wang L, Yang R, Zhao L, Zhang X, Xu T and Cui M: Basing on uPAR-binding fragment to design chimeric antigen receptors triggers antitumor efficacy against uPAR expressing ovarian cancer cells. Biomed Pharmacother 117: 109173, 2019.

50. Pavon MA, Arroyo-Solera I, Cespedes MV, Casanova I, Leon X and Mangues R: uPA/uPAR and SERPINE1 in head and neck cancer: Role in tumor resistance, metastasis, prognosis and therapy. Oncotarget 7: 57351-57366, 2016.

51. Wang P, Ma M and Zhang S: EGF-induced urokinase plasminogen activator receptor promotes epithelial to mesenchymal transition in human gastric cancer cells. Oncol Rep 38: 2325-2334, 2017.

52. Manzoni C, Kia DA, Vandrovcova J, Hardy J, Wood NW, Lewis PA and Ferrari R: Genome, transcriptome and proteome: The rise of omics data and their integration in biomedical sciences. Brief Bioinform 19: 286-302, 2018

53. Yoshimoto Y, Sasaki Y, Murata K, Noda SE, Miyasaka Y, Hamamoto J, Furuya M, Hirato J, Suzuki Y, Ohno T, et al: Mutation profiling of uterine cervical cancer patients treated with definitive radiotherapy. Gynecol Oncol 159: 546-553, 2020.

This work is licensed under a Creative Commons Attribution-NonCommercial-NoDerivatives 4.0 International (CC BY-NC-ND 4.0) License. 